\title{
Screening of antenatal patients in a multiethnic community for $\beta$ thalassaemia trait
}

\author{
BARBARA J BAIN \\ From the Department of Haematology, St Mary's Hospital Medical School, London
}

SUMMARY An investigation of the reliability of screening tests for $\beta$ thalassaemia trait in pregnant women was carried out as part of a programme to predict $\beta$ thalassaemia major in the fetus. Women with a mean corpuscular volume (MCV) of less than $83 \mathrm{fl}$ were examined further, and the reliability of various red cell indices as screening tests was assessed and compared.

Over three years 696 women were found to be microcytic and were investigated further. If no abnormal haemoglobin was found by cellulose acetate electrophoresis at alkaline $\mathrm{pH}$, haemoglobin $\mathrm{A}_{2}$ estimation was performed. Beta thalassaemia trait was diagnosed in $56(8 \%)$ of the microcytic women. Both the MCV and the mean corpuscular haemoglobin (MCH) were found to be suitable screening tests for detecting patients who required further investigation. Women found to have $\beta$ thalassaemia trait or a functionally equivalent disorder were of varied ethnic origins. Of 58 such women, partners were investigated in 45 instances, and three pregnancies at risk of $\beta$ thalassaemia major were identified.

Investigations for $\beta$ thalassaemia trait should preferably be carried out before pregnancy but for those already pregnant investigation should be carried out, irrespective of whether the patient seems to be iron deficient. It is advisable that partners of women with $\beta$ thalassaemia trait have haemoglobin electrophoresis, whatever their red cell indices, as double heterozygosity for either haemoglobin $\mathrm{S}$ or haemoglobin $\mathrm{E}$ and $\beta$ thalassaemia may produce severe disease.

Since the prenatal diagnosis of $\beta$ thalassaemia was first achieved in 1975 rapid technical advances have taken place: in many cases prenatal diagnosis can now be accomplished by the end of the first trimester of pregnancy. Such prenatal diagnosis depends on identification of at risk pregnancies. In highly motivated, tightly knit communities with a high incidence of $\beta$ thalassaemia trait identification of high risk couples may be achieved around the time of marriage, but in other communities diagnosis often depends on rapid identification of at risk pregnancies after presentation to an antenatal clinic. Paddington and North Kensington district is an inner city, socially deprived, multiethnic community with a high incidence of haemoglobinopathies and thalassaemia trait. A comprehensive screening programme for the identification of pregnancies at risk of thalassaemia major was introduced into all district antenatal clinics during 1983 , at the same time as a programme to detect clinically important haemoglobinopathies. The results of screening for pregnancies at risk of thalassaemia major are reported here, the first three years of the programme having been assessed.

Accepted for publication 26 January 1988

\section{Patients and methods}

All women presenting to the antenatal clinic had a blood sample taken on first attendance for a full blood count and blood film. The full blood count was performed on a Coulter Counter model S, standardised with Coulter Electronics Quality Control material 4C. The packed cell volume (PCV) and therefore the mean corpuscular volume (MCV) were "corrected" for $3 \%$ plasma trapping so that PCV results would be on average $3 \%$ lower than a microhaematocrit reading. (This practice has been generally followed in British haematology laboratories since about 1974-5). The patient's ethnic origin was recorded on the haematology request form by antenatal clinic staff using the following general categories: black, Mediterranean, caucasian (which excluded caucasians of Mediterranean or Indian subcontinent origin), Asian (Indian, Pakistani, Bangladeshi and East African Asian), oriental (other Asian) and other (Middle Eastern, north African, South American etc).

The blood film was examined and the full blood count assessed by haematological scientific or medical staff, or both, who started haemoglobin electrophoresis and haemoglobin $\mathrm{A}_{2}$ estimation when the 
MCV fell below $83 \mathrm{fl}$ and the test seemed to be indicated. During the first year investigation was sometimes thought not to be indicated despite a low MCV if the women were identified as caucasian or if the indices and blood film strongly suggested iron deficiency. When it was found that during the first year a total of six patients had been diagnosed later in pregnancy, rather than at booking, the policy was amended. Thereafter investigation was started on all pregnant women with an MCV of less than $83 \mathrm{fl}$, irrespective of ethnic origin or apparent iron status. The cut off point of $83 \mathrm{fl}$ was chosen because this is the 2.5 percentile for the MCV of healthy, non-pregnant women, and men in our laboratory. Screening electrophoresis was performed on cellulose acetate at a $\mathrm{pH}$ of $8 \cdot 2-8 \cdot 6$. Patients discovered to have a haemoglobinopathy on screening electrophoresis did not have a haemoglobin $A_{2}$ estimation. In the other patients haemoglobin $A_{2}$ was estimated by anion exchange chromatography (Helena Beta-thal $\mathrm{HbA}_{2}$ Quick Column). A haemoglobin $A_{2}$ concentration of less than $3.4 \%$ was accepted as normal and greater than $4.0 \%$ as diagnostic of $\beta$ thalassaemia trait. When the concentration fell between 3.4 and 4.0 the assay was usually repeated and a further sample was requested for a further assay. Haemoglobin $F$ was estimated only if a band was visible in the position of $F$ on screening electrophoresis.

When a patient was found to have $\beta$ thalassaemia trait a blood specimen was requested from her partner. A full blood count and haemoglobin electrophoresis were performed on this blood specimen, and if the $\mathrm{MCV}$ was less than $83 \mathrm{fl}$ the haemoglobin $\mathrm{A}_{2}$ concentration was measured.

Couples found to be at risk of having a child with thalassaemia major were given a full explanation by obstetric staff, and, when the period of gestation permitted, were offered antenatal diagnosis and termination of pregnancy. The partner was also investigated in all women of oriental origin in whom $\alpha$ thalassaemia trait was a possibility. The investigation and treatment of other microcytic patients was left to the individual obstetrician.

Three years after its introduction the results of the programme were assessed. The suitability of the criteria used for investigation were included in the assessment.

\section{Results}

Six hundred and ninety six antenatal patients were investigated as a result of a full blood count at booking which showed an MCV of less than $83 \mathrm{fl}$. In 96 women $(13.8 \%)$ the cellulose acetate electrophoresis showed an abnormal haemoglobin, which in two cases was haemoglobin Lepore. In the other 600 women a haemoglobin $\mathrm{A}_{2}$ estimation disclosed 56 patients who had $\beta$ thalassaemia trait $(8 \%$ of total group screened, $9 \cdot 3 \%$ of patients having haemoglobin $\mathrm{A}_{2}$ estimations). In further analysis the two patients with haemoglobin Lepore trait have been grouped with the patients with $\beta$ thalassaemia trait as the two conditions are of the same clinical importance. The prevalence of $\beta$ thalassaemia trait decreased from $50 \%$ in those with an MCV of less than $65 \mathrm{fl}$ to $0.4 \%$ of those with an MCV of 80-82 $\mathrm{fl}$ (table 1 ). The 58 patients with thalassaemia trait had had a total of 73 pregnancies for which haematological data from our laboratory were available, the extra 15 pregnancies being both before and after the index pregnancy in which thalassaemia trait was diagnosed. Of the $73 \mathrm{MCVs}$ measured on booking at the antenatal clinic, 71 fell below $78 \mathrm{fl}$, the two remaining values being 79 and $80 \mathrm{fl}$.

In 55 pregnancies for which serial full blood counts were available the $\mathrm{MCV}$ was found to rise on average by $2.6 \mathrm{fl}$ (range $0-10 \mathrm{fl}$, median $2 \mathrm{fl}$ ) from booking $\mathrm{MCV}$ to peak level. In one patient the MCV rose for 80 to $81 \mathrm{fl}$ but in none did a rise above $82 \mathrm{fl}$ occur.

The usefulness of various formulae which have been proposed for identification of thalassaemia trait was assessed. Two of these, the discriminant function of England and Fraser ${ }^{1}$ (discriminant function $=$ MCV $-[\mathrm{Hb} \times 5]-$ red cell count $(\mathrm{RBC})-3.4)$ and the formula of Mentzer ${ }^{2}$ (MCV/RBC), are stated by their originators to be unreliable in pregnancy. This was confirmed as they identified only $19 \%$ and $34 \%$, respectively, of the patients with $\beta$ thalassaemia trait. The formula of Srivastava ${ }^{3} \mathrm{MCH} / \mathrm{RBC}$ ) was even less useful as only $5 \%$ of patients were identified. If the cut off point for England and Fraser's discriminant func-

Table 1 Results of screening antenatal patients with MCVs falling within various ranges for $\beta$ thalassaemia trait and abnormal haemoglobins

\begin{tabular}{|c|c|c|c|c|c|c|}
\hline $\begin{array}{l}\text { Mean corpuscular volume (MCV) (fl) } \\
\text { Total No investigated } \\
\text { No abnormal haemoglobin or } \\
\text { increase in HbA, detected } \\
\beta \text { thalassaemia trait* (plus Hb Lepore) } \\
\text { Haemoglobinopathy* (except Hb Lepore) } \\
\text { Percentage having either } \beta \text { thalassaemia } \\
\text { trait or an abnormal haemoglobin }\end{array}$ & $\begin{array}{r}17(50) \\
4(12) \\
62\end{array}$ & $\begin{array}{l}25(35) \\
10(14) \\
49\end{array}$ & $\begin{array}{l}70-74 \\
110 \\
81\end{array}$ & $\begin{array}{l}75-79 \\
205 \\
174 \\
\\
3(1 \cdot 5) \\
28(13 \cdot 5) \\
15\end{array}$ & 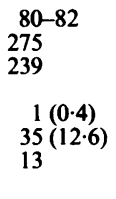 & $\begin{array}{l}\text { Total } \\
696 \\
544 \\
\\
58(8 \cdot 3) \\
94(13 \cdot 5) \\
21 \cdot 8\end{array}$ \\
\hline
\end{tabular}

*The percentage of patients in each MCV range having the specified abnormality is shown in parentheses. 
tion was taken as 15 rather than zero when applied to pregnant subjects, as suggested by White and coworkers, ${ }^{4}$ there were still $12 \%$ of subjects with $\beta$ thalassaemia trait not identified. The formula of Shine and $\mathrm{Lal}^{5}\left(\mathrm{MCV}^{2} \times \mathrm{MCH}\right)$, however, successfully identified 57 of 58 index pregnancies in patients with $\beta$ thalassaemia trait. If the cut off point was raised from 1530 $(\times 100)$ to $1620(\times 100)$ all patients were identified. These cut off points, would have avoided unnecessary haemoglobin $\mathrm{A}_{2}$ estimations in $65 \%$ and $58 \%$, respectively, of 100 consecutive pregnant women who were found to have neither $\beta$ thalassaemia trait nor a haemoglobinopathy.

The mean corpuscular haemoglobin $(\mathrm{MCH})$ was also assessed as to whether it could be used to screen for $\beta$ thalassaemia trait. All MCHs at booking fell below the 2.5 percentile for healthy subjects, which in our laboratory is $27 \cdot 1 \mathrm{pg}$. The highest level observed at booking was $25.9 \mathrm{pg}$. If a cut off point of $26 \mathrm{pg}$ were chosen all women with $\beta$ thalassaemia trait would have been detected with a $29 \%$ decrease in workload.

The haematological opinion on the blood film and red cell indices was found to be unreliable for screening. In nine of the 58 index pregnancies the laboratory specifically suggested a diagnosis of iron deficiency. Target cells and basophilic stippling were often absent while pencil cells were sometimes present. The haemoglobin concentration was often low (mean 10.4 $\mathrm{g} / \mathrm{dl}$, observed range $7 \cdot 9-12 \cdot 4 \mathrm{~g} / \mathrm{dl}$ ).

The ethnic origin of the patients found to have $\beta$ thalassaemia trait is shown in table 2, together with the percentage they represent of patients of the given ethnic group who were investigated because of a low $\mathrm{MCV}$. The prevalence of $\beta$ thalassaemia trait (plus haemoglobin Lepore) in the patients investigated varied from $1.4 \%$ in the caucasian group to $17.8 \%$ in the oriental group.

Booking at the antenatal clinic was often delayed, less than half the women booking during the first trimester. Women of Mediterranean origin, who might be expected to be best informed about $\beta$ thalassaemia trait, did not present to the antenatal

Table 2 Ethnic origin of patients found to have $\beta$ thalassaemia trait in relation to number of patients of given ethnic group screened

\begin{tabular}{lll}
\hline & Patients screened & $\begin{array}{l}\beta \text { thalassaemia trait } \\
(\text { No/\% } / \%\end{array}$ \\
\hline Black & 228 & $12+1$ Lepore $(5 \cdot 7)$ \\
Caucasian & 72 & 1 Lepore $(1 \cdot 4)$ \\
Indian & 198 & $17(8 \cdot 6)$ \\
Mediterranean & 74 & $12(16 \cdot 2) \dagger$ \\
Oriental & 56 & $10(17 \cdot 8) \ddagger$ \\
Other & 61 & $5(8 \cdot 2)$ \\
\hline
\end{tabular}

* No record of ethnic origin was available in 7 patients; †Greek, Italian, Cypriot, Spanish; $\ddagger$ Chinese, Thai, Malaysian, Indonesian, Filippino; Moroccan, Iranian, Iraqui clinic appreciably earlier than other women.

During the 58 index pregnancies 45 partners were investigated. Of the 13 instances of partners not being investigated eight occurred during the first six months of the programme and in two of these instances patients did not continue to attend the antenatal clinic. Of the five partners not tested during the subsequent two and a half years, the reasons were miscarriage, alleged rape, pending divorce, late booking with partner outside the United Kingdom and late initiation of test by laboratory. Of the 45 partners tested, four were found to have a clinically important abnormality which was $\beta$ thalassaemia trait in three cases and sickle cell trait in one case. Of the three couples, all of Mediterranean origin, at risk of having a child with $\beta$ thalassaemia major, two accepted antenatal diagnosis and one declined it. All produced normal infants.

\section{Discussion}

Since antenatal diagnosis of $\beta$ thalassaemia has become available, births of children with thalassaemia major have fallen in various Mediterranean countries to between 10 and $50 \%$ of the 1970 rate. At the same time the rate in the United Kingdom remains at almost $70 \%$ of the 1970 level. ${ }^{6}$ In the United Kingdom about two thirds of thalassaemia major births used to be to Cypriot parents and about one third to Indian or Pakistani parents ${ }^{7}$ but the latter group now predominates. ${ }^{8}$ To give all parents at risk of having a child with thalassaemia major the opportunity to decide whether to continue with a pregnancy when the fetus is affected, requires that antenatal diagnosis of thalassaemia trait be offered to all at risk mothers as early in pregnancy as possible. In 1983 the Paddington and North Kensington District introduced a screening programme with this aim, the results of which have now been assessed. Screening patients who are already pregnant presents special problems. Firstly, many patients first present at the antenatal clinic quite late in pregnancy. It is for this reason that we chose to have relevant tests initiated by the laboratory staff, although it remains the responsibility of clinical staff to ensure that all tests necessary for the optimal management of the patient are performed. Secondly, the physiological fall of haemoglobin concentration consequent on the haemodilution of pregnancy makes it less likely that $\beta$ thalassaemia trait will be suspected on the basis of pronounced microcytosis with little reduction of the haemoglobin concentration. (The physiological rise of MCV during pregnancy seems, from this study, to be of lesser importance). Thirdly, the high incidence of iron deficiency in pregnancy, particularly in socially deprived or vegetarian women, complicates diagnosis; the red cell indices are less informative and iron deficiency may also cause 
sufficient lowering of the haemoglobin $\mathrm{A}_{2}$ concentration that diagnosis based on this variable becomes less reliable. $^{9}$

The basis of the screening programme was the identification of microcytic subjects, but the primary purpose of this study was to assess the efficiency of the programme rather than to investigate the causes of microcytosis during pregnancy. Of the microcytic women investigated, $21.8 \%$ were found to have either an abnormal haemoglobin or $\beta$ thalassaemia trait. The abnormal haemoglobins most commonly observed were $\mathrm{S}, \mathrm{C}$, and $\mathrm{E}$, all of which are known to be associated with microcytosis. ${ }^{1011}$ The cause of microcytosis in the other $78 \%$ was not systematically investigated, management being left to the individual obstetricians. We are aware, however, of the high prevalence of iron deficiency among pregnant women in our district, particularly but not solely among women from the Indian subcontinent. Among black subjects $\alpha$ thalassaemia trait also contributes to the occurrence of microcytosis; its prevalence can be $30 \%$ or higher in those of West Indian origin. ${ }^{12}$

The data presented here relate to the first three years of the screening programme. Although the criteria for investigation were changed at the end of the first year, it seems preferable, for a number of reasons, to include all the data. Firstly, the extension of screening to all those groups did not disclose $\beta$ thalassaemia trait in any unexpected ethnic groups, although it decreased the likelihood that any case would be inadvertently missed. Secondly, although a provisional diagnosis of iron deficiency led to late diagnosis in some patients during the first year, no cases are known too have been missed for this reason. Thirdly, the results from the entire three years as presented here permit a realistic assessment of the practical problems which will be met by hospitals attempting to introduce a comprehensive screening programme.

The MCV was found to be suitable for the detection of pregnant women requiring investigation for $\beta$ thalassaemia trait. From this study, it seems that a cut off point of $83 \mathrm{fl}$ (when a $3 \%$ correction for plasma trapping is applied) will identify most cases of $\beta$ thalassaemia trait. The return from investigating women with an MCV of 81 and $82 \mathrm{fl}$ is very low, and a cut off point of $<81$ fl could reasonably be supported. This would avoid about $35 \%$ of unnecessary haemoglobin $\mathrm{A}_{2}$ estimates. Application of the formula ${ }^{5} \mathrm{MCV}^{2} \times \mathrm{MCH}$ (which is not affected by the haemodilution of pregnancy) would avoid about $58 \%$ of unnecessary testing, but would add extra complexity to the selection of patients for investigation. Other formulae were not found to be useful. The $\mathrm{MCH}$ seems to be as satisfactory as the MCV, and use of this variable would have the advantage that identical results should be produced by all laboratories, whereas the MCV is influenced by both the technology used in its measurement and in the method of standardising the instrument used. The use of the $\mathrm{MCH}$ rather than the MCV, however, would require a larger number of women to be investigated if all cases were to be detected. Whether this difference would be of such a magnitude as to be of practical importance cannot be determined from this study.

The return from investigating caucasians of northern European origin is low, although problems exist in their identification. For example, one of our patients now included in the Mediterranean group was found to have an Italian father only after the laboratory had made the diagnosis of $\beta$ thalassaemia trait. All other ethnic groups should be investigated. Subjects we have categorised as oriental are at risk of $\alpha$ thalassaemia trait and of producing a fetus with haemoglobin Barts hydrops fetalis, but those who are microcytic also have a high incidence of $\beta$ thalassaemia trait. The incidence is also appreciable in microcytic women from the Indian subcontinent, in black women, and in the extremely heterogenous group we have classified as "other". In a multiethnic community it may be most practicable to investigate all women with an MCV or $\mathrm{MCH}$ below a defined level, irrespective of apparent ethnic origin.

It is preferable that investigations for $\beta$ thalassaemia trait be carried out before pregnancy but this is usually only possible in ethnic groups with a high prevalence of $\beta$ thalassaemia trait. When patients who are already pregnant are being screened investigations must be carried out irrespective of whether the patient seems to be iron deficient. Because of the fall of haemoglobin $\mathrm{A}_{2}$ concentration, which occurs with iron deficiency, some cases of $\beta$ thalassaemia trait may be missed, but time does not permit the prior correction of the deficiency state which is the preferred course in nonpregnant patients.

It is advisable that partners of women with $\beta$ thalassaemia trait have haemoglobin electrophoresis regardless of their red cell indices, as double heterozygosity for either haemoglobin $S$ or haemoglobin $\mathrm{E}$ and $\beta$ thalassaemia trait may produce severe disease.

I thank the members of the paediatrics, obstetrics, and haematology departments of the Paddington and North Kensington District who collaborated in the establishment of this programme, and in particular, Dr Nellie Adjaye and Mr P Steer.

\section{References}

1 England JM, Fraser PM. Differentiation of iron deficiency from thalassaemia trait by routine blood count. Lancet 1973;i:44952. 
2 Mentzer WC. Differentiation of iron deficiency from thalassaemia trait. Lancet 1973;i:882.

3 Srivastava PC. Differentiation of thalassaemia minor from iron deficiency. Lancet 1973;ii:154-5.

4 White JM, Richards R, Byrne $M$ et al. Thalassaemia trait in pregnancy. J Clin Pathol 1985;38:810-7.

5 Shine J, Lal S. A strategy to detect $\beta$ thalassaemia trait. Lancet 1977;i:692-4.

6 Cao A, Pirastu M, Rostaelli C. The prenatal diagnosis of thalassaemia. Br J Haematol 1986;63:215-20.

7 Modell B, Ward RHT, Fairweather DVI. Effect of introducing antenatal diagnosis on reproductive behaviour of families at risk for thalassaemia major. $\mathrm{Br} \mathrm{Med} J$ 1980;280:1347-50.

8 Modell B, Petrou M, Ward RHT, et al. Effect of fetal diagnostic testing on birth-rate of thalassaemia major in Britain. Lancet 1984;ii:1383-6.

9 Wasi P, Disthasongchan P, Na-Nakorn S. The effects of iron deficiency on the levels of hemoglobins $\mathrm{A}_{2}$ and E. J Lab Clin Med 1968;71:85-91.

10 Sheehan RG, Frenkel EP. Influence of hemoglobin phenotype on the mean erythrocyte volume. Acta Haematol 1983;69:260-5.

11 Lachant NA. Hemoglobin E: an emerging hemoglobinopathy in the United States. Am J Hematol 1987;25:449-62.

12 Serjeant GR. Serjeant BE, Forbes M, Hayes RJ, Higgs DR. Haemoglobin gene frequencies in the Jamaican population; a study of 100,000 newborns. Br J Haematol 1986;64:253-62.

Requests for reprints to: Dr Barbara J Bain, Department of Haematology, St Mary's Hospital Medical School, London W2 1PG, England. 